\title{
Evaluation of the gonococcal complement-fixation test
}

\author{
C. S. RATNATUNGA \\ Whitechapel Clinic, The London Hospital
}

The gonococcal complement-fixation test (GCFT), based on the same principle as the Wassermann reaction (WR), has been in use for over 60 years. The test was applied for the first time, using a culture of the gonococcus as antigen, by Müller and Oppenheim (1906) to establish the diagnosis in a case of arthritis. Teague and Torrey (1907) suggested that negative results in the GCFT were due to different strains of gonococci and showed that a 'polyvalent' antigen consisting of several strains gave better results. Schwartz and McNeil (1911) confirmed the superiority of a 'polyvalent' antigen. They found that cases which gave negative results with an antigen made from six strains gave definite positive results when examined with an antigen made from twelve strains.

Schwartz and McNeil (1912) considered that the GCFT was absolutely specific for the gonococcus because in it there was a true antigen-antibody combination. Kolmer and Brown (1914) thought that the reaction was not generally as satisfactory as the WR because the quantity of gonococcal antibody was much smaller than that of reagin unless the disease was widespread. Shupe (1916) believed that, while the test was not infallible, it was the most reliable method available to determine the absence of gonococci. He stressed that the results should be correlated with the other findings in the case.

Weiss and Arnold (1938) showed that increasing the amounts of serum tested gave more frequent positive reactions in gonorrhoea without increasing non-specific reactions to a disturbing degree. The lower level of antigonococcal antibody in serum from a patient suffering from gonorrhoea as compared with anti-syphilitic antibody in the serum of a patient suffering from syphilis was probably due to the fact that the former infection was localized while the latter was generalized.

An objection to using large amounts of serum in

Received for publication January 27, 1971

Present address: Royal Free Hospital, Gray's Inn Road, London WC1X 8LF the GCFT was the possibility of an increase in anti- iv complementary reactions, although Price (1933) did 6

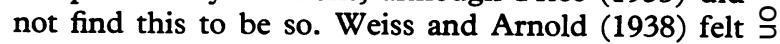
that this difficulty could be overcome if sera were $\rightarrow$ correctly obtained, preserved, and prepared for the test. They considered that a positive GCFT indicated the presence of gonococcal foci in the body; the only non-specific reaction worthy of mention was that due to epidemic meningitis, but they thought that this should not cause confusion.

The possibility of cross-fixation with antibodies to allied organisms such as Neisseria meningitidis and Neisseria catarrhalis, was considered by most workers, but the general view was that such cross-fixation was usually weak and would not cause errors in diagnosis.

Wilkinson (1952), in a study of cultures from 1,275 patients attending the Whitechapel Clinic of The London Hospital for the first time and 350 patients attending the Ante-natal Clinic of the same hospital, found strains of Neisseria other than gonococci in thirteen cases. The GCFT was negative in twelve of these; in the thirteenth the result was not available.

Considerable discussion took place in the 1930s and the early 1940s regarding the value of the GCFT in the diagnosis of gonorrhoea. Some authorities, such as Price (1931), maintained that a positive result was definite evidence of gonorrhoea and considered that the test had a value in gonorrhoea comparable to that of the WR in syphilis: conversely, Harkness (1944) thought that the GCFT could be discarded because of the frequency of persistent positive reactions that had no clinical significance. Later, Price (1949a) came to believe that the test was 'but a shadow of its former self', though it was of value in the diagnosis of the complications of gonorrhoea. The GCFT gradually fell into disrepute because positive results were frequently obtained in the cases of asymptomatic patients in which gonorrhoea could not be confirmed bacteriologically. No doubt the rapid cures achieved by penicillin played an important part in the discontinuance of the GCFT as a routine test in the diagnosis of gonorrhoea. 
Recently, interest in the value of the test has revived. Ramanarayana Murti, Rajyalakshmi, and Perin Devi (1961) tested the sera of 44 women with tubo-ovarian masses; in sixteen cases gonococci had been found by smear and/or culture and the GCFT was positive in fifteen; in one in which other Neisseria (not gonococci) had been obtained, the GCFT was positive. In the remaining 27 a positive result was found in ten. These authors concluded that the test was of value in long-standing, but not in recent, gonorrhoea. Magnusson and Kjellander (1965) examined the sera in 200 cases of uncomplicated gonorrhoea and 100 cases of complicated gonorrhoea in both sexes; they considered the test to be highly specific and a useful additional procedure in the diagnosis of gonorrhoea.

\section{Material and methods}

For many years the GCFT has been performed routinely on sera from all new patients who attend the Whitechapel Clinic. The test was modified in July, 1966. This communication presents the results of the test on the sera of 1,873 patients seen at the clinic between July, 1966, and April, 1967, when it was discontinued as a routine procedure. An attempt was made to determine the significance of a positive GCFT. The results can give the findings only in a group of patients selected because they had visited a clinic for sexually-transmitted disease; the men usually attended because of symptoms and the women because they were sexual contacts of infected men.

Table I shows the clinical material classified by diagnosis and sex.

At the initial visit of a female patient specimens were taken from the urethra, cervix, vagina, and rectum for direct microscopy of Gram-stained smears and for culture. A wet preparation was also made from vaginal material for examination for Trichomonas vaginalis.

At the first visit of a male patient specimens for smear and culture were taken from the urethra and, when indicated, from the rectum. A sample of blood was taken from each for the GCFT and for serological tests for syphilis. It was intended to repeat the GCFT 3 months later when the serological tests for syphilis were being
TABLE I Diagnosis in 1,873 patients, by sex

\begin{tabular}{|c|c|c|c|}
\hline Diagnosis & Men & Women & Total \\
\hline $\begin{array}{l}\text { Uncomplicated gonorrhoea } \\
\text { Gonococcal proctitis }\end{array}$ & $\begin{array}{r}400 \\
11\end{array}$ & $250^{\star} \star$ & 650 \\
\hline $\begin{array}{l}\text { Complicated gonorrhoea } \\
\text { (epididymitis, salpingitis, }\end{array}$ & & & \\
\hline bartholinitis) & 4 & $44^{\star}$ & 48 \\
\hline Non-specific urethritis & 300 & - & 300 \\
\hline Non-specific salpingitis & - & 64 & 64 \\
\hline $\begin{array}{l}\text { Other sexually-transmitted diseases } \\
\text { (excluding syphilis) }\end{array}$ & 200 & 200 & 400 \\
\hline Non-venereal cases & 200 & 200 & 400 \\
\hline rotal & 1,115 & 758 & 1,873 \\
\hline
\end{tabular}

*Gonococcal proctitis was found in 33.6 per cent. (99 in 294) of female patients. In thirteen women (4.3 per cent. of those found to be infected with gonorrhoea), there was gonococcal proctitis only without evidence of gonorrhoea in the other sites

repeated, but this proved to be possible only in a small proportion of cases.

The technique followed in performing the GCFT was essentially the same as that described by Price $(1949 \mathrm{~b}$, 1950), the only modification being that the antigen originally used was replaced by a suspension of intact gonococci prepared from a number of freshly-isolated strains.

\section{Results}

In uncomplicated gonorrhoea the GCFT was positive (Table II) almost twice as often in women (34 per cent.) as in men (18 per cent.). In complicated gonorrhoea in women the test was positive only a little more frequently (41 per cent.) than in uncomplicated gonorrhoea and the difference was not statistically significant. There were only four cases of complicated gonorrhoea in men, the GCFT being positive in one.

In none of the comparison groups (Table III) was the GCFT negative in all cases. The test was positive in 12.5 per cent. of cases of non-specific salpingitis and in 4.7 per cent. of cases of non-specific urethritis. The test was positive in 2.5 per cent. of men suffering from other sexually-transmitted diseases and in 6.5 per cent. of women in the same category. In the cases

TABLE II Results of GCFT in gonorrhoea, by diagnosis and sex

\begin{tabular}{|c|c|c|c|c|c|}
\hline \multirow{2}{*}{ Sex } & \multirow{2}{*}{ Diagnosis } & \multicolumn{4}{|c|}{ Results of GCFT } \\
\hline & & No. & Per cent. & Negative & Total \\
\hline Men & $\begin{array}{l}\text { Uncomplicated gonorrhoea } \\
\text { Complicated gonorrhoea } \\
\text { Rectal gonorrhoea }\end{array}$ & $\begin{array}{r}72 \\
1 \\
1\end{array}$ & $\begin{array}{l}18 \\
9 \cdot 1\end{array}$ & $\begin{array}{r}328 \\
3 \\
10\end{array}$ & $\begin{array}{r}400 \\
4 \\
11\end{array}$ \\
\hline \multirow[t]{2}{*}{ Women } & $\begin{array}{l}\text { Uncomplicated gonorrhoea } \\
\text { Complicated gonorrhoea }\end{array}$ & $\begin{array}{l}85 \\
18\end{array}$ & $\begin{array}{l}34 \\
41\end{array}$ & $\begin{array}{r}165 \\
26\end{array}$ & $\begin{array}{r}250 \\
44\end{array}$ \\
\hline & Total & \multicolumn{2}{|l|}{103} & 191 & 294 \\
\hline
\end{tabular}


TABLE III Results of GCFT in conditions other than gonorrhoea, by sex

Diagnosis

Results of GCFT

Non-specific urethritis

Non-specific salpingitis

Other sexually-transmitted diseases
Non-venereal cases

\begin{tabular}{ll}
\hline \multicolumn{2}{l}{ Men } \\
\hline Positive \\
\hline No. & Per cent. \\
\hline 14 & $4 \cdot 7$ \\
\hline 5 & 2.5 \\
6 & 3
\end{tabular}

$\begin{array}{ll}\text { Negative } & \text { Total } \\ & \\ \frac{300}{195} & \frac{2}{200} \\ 194 & 200\end{array}$

\begin{tabular}{lr}
\multicolumn{2}{l}{ Women } \\
\hline Positive \\
\hline No. & Per cent. \\
\hline- & \\
8 & 12.5 \\
13 & 6.5 \\
13 & 6.5
\end{tabular}

TABLE IV History of past infection in patients with positive GCFT tests, by sex

\begin{tabular}{|c|c|c|c|c|c|c|}
\hline \multirow{2}{*}{ Sex } & \multirow{2}{*}{ Diagnosis } & \multicolumn{5}{|l|}{ Past history of } \\
\hline & & $\begin{array}{l}\text { Urethritis or genital } \\
\text { infection }\end{array}$ & Bronchitis and/or asthma & Both & Neither & Total \\
\hline \multirow[t]{6}{*}{ Men } & \multirow{5}{*}{$\begin{array}{l}\text { Gonorrhoea }\left\{\begin{array}{l}\text { Uncomplicated } \\
\text { Complicated } \\
\text { Rectal }\end{array}\right. \\
\text { Non-specific urethritis } \\
\text { Other sexually-transmitted diseases } \\
\text { Non-venereal }\end{array}$} & 34 & 4 & - & 34 & 72 \\
\hline & & $\overline{1}$ & 二 & - & 1 & $\begin{array}{l}1 \\
1\end{array}$ \\
\hline & & 9 & - & - & 5 & 14 \\
\hline & & \multirow{2}{*}{$\begin{array}{l}2 \\
2\end{array}$} & $\overline{-}$ & - & 3 & 5 \\
\hline & & & & - & 4 & 6 \\
\hline & Total & $48 \quad$ (48.4 per cent.) & $4 \quad$ (4 per cent.) & - & 47 & 99 \\
\hline \multirow[t]{5}{*}{ Women } & Gonorrhoea $\left\{\begin{array}{l}\text { Uncomplicated } \\
\text { Complicated }\end{array}\right.$ & 30 & - & - & 55 & 85 \\
\hline & \multirow{3}{*}{$\begin{array}{l}\text { Non-specific salpingitis } \\
\text { Other sexually-transmitted diseases } \\
\text { Non-venereal }\end{array}$} & \multirow{2}{*}{$\begin{array}{l}8 \\
5\end{array}$} & \multirow{2}{*}{ 二 } & - & $\underline{9}$ & $\begin{array}{r}18 \\
8\end{array}$ \\
\hline & & & & - & 8 & $\begin{array}{r}0 \\
13\end{array}$ \\
\hline & & 3 & $\overline{-}$ & - & 10 & 13 \\
\hline & Total & $55 \quad(40 \cdot 1$ per cent. $)$ & - & - & 82 & 137 \\
\hline
\end{tabular}

of patients without evidence of sexually-transmitted disease, the test was positive in 3 per cent. of men and 6.5 per cent. of women. The greater frequency of positive results in women in the two latter groups, though apparently twice that in men as in uncomplicated gonorrhoea, is not statistically significant.

There was a past history of urethritis in 48 (48.4 per cent.) of the 99 male cases in which there was a positive GCFT (Table IV). Urethral discharge was considered in one category as some patients were uncertain whether their previous infections were gonococcal or non-gonococcal and records of past infections were generally available only if the patient had previously attended the Whitechapel Clinic. Among women a past history of gonorrhoea or of genital inflammation, such as non-specific salpingitis, trichomoniasis, or candidiasis, was present in 55 ( 40.1 per cent.) of the 137 seropositive cases. In the seronegative group, $297(29 \cdot 1$ per cent.) of men and 107 (17.2 per cent.) of women gave such a history (Table $\mathrm{V}$, overleaf). In non-specific salpingitis a past history of genital inflammation (six of them of gonorrhoea) was noted in all eight seropositive cases. Among those with a negative test result, 29 (50 per cent.) gave a past history of genital inflammation (Tables IV and V).
A past history of bronchitis and/or asthma had been recorded in only four (4 per cent.) of the 99 seropositive male cases (Table IV). Among the 1,016 seronegative men such a history had been obtained from 24, while a further six (making up 3 per cent.) had suffered from both bronchitis and/or asthma and urethritis in the past (Table V). None of the 137 seropositive female patients gave a past history of bronchitis and/or asthma, while among the 621 sero- 을 negative women, seventeen ( 3 per cent.) gave such a $D$ history and a further two had had both bronchitis and/or asthma and genital inflammation previously $N$ (Tables IV and V). This was a retrospective study and a history of bronchitis and/or asthma would not $\tilde{O}$ have been specifically asked for from every patient.

In the cases of the 72 GCFT-positive male patients suffering from uncomplicated gonorrhoea, the dur- $Q$ ation of symptoms was less than 3 days in 35, and between 4 and 7 days in 23 (Table VI, overleaf). Thus, $\stackrel{?}{?}$ in 58 (80.6 per cent.) the duration of symptoms was 7 days or less. Of these patients, 22 (37.3 per cent.) gave a definite past history of gonorrhoea and a further nine of urethritis. Of the 85 GCFT-positive female patients suffering from uncomplicated gonorrhoea, 36 were asymptomatic, and in 25 the symptoms were of 7 days' duration or less; eighteen (29.5 per cent.) of 
TABLE $\mathrm{v}$ History of past infection in patients with negative GCF tests, by sex

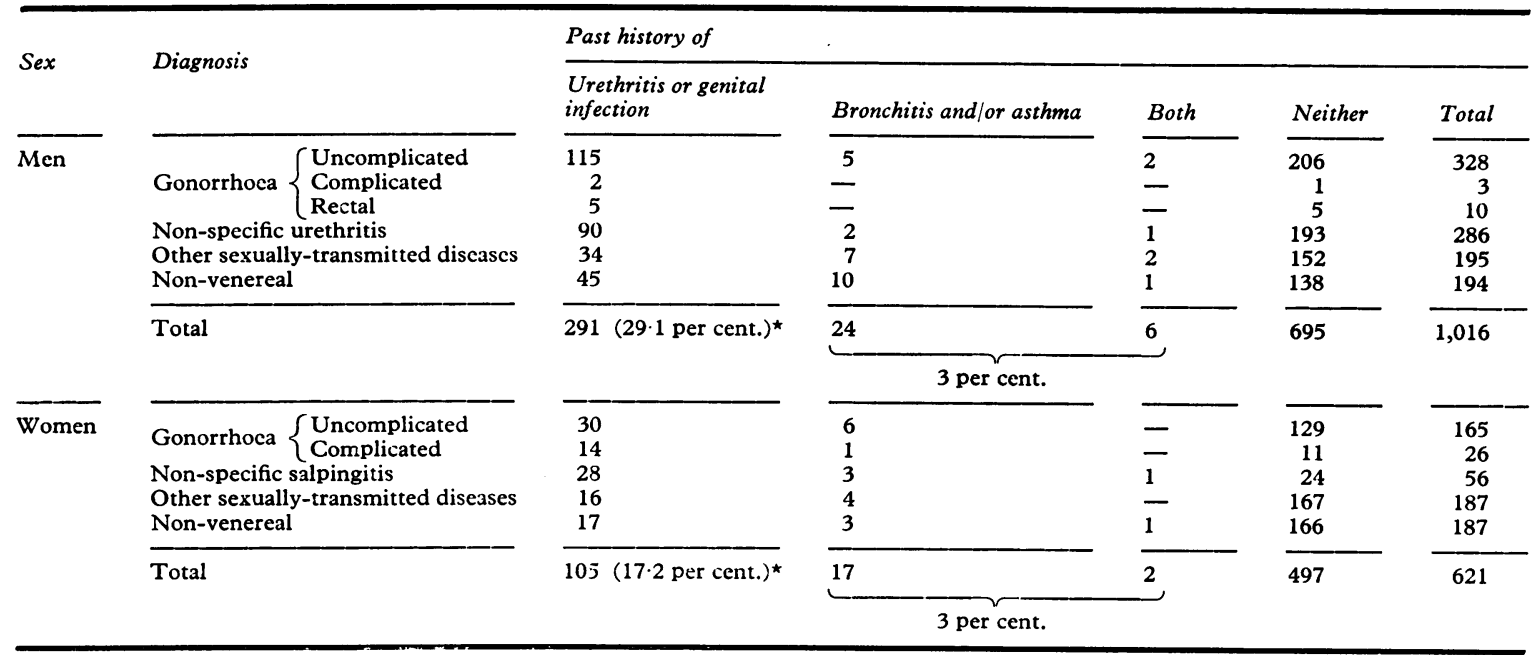

*When the 6 and the 2 in col. 4 are included respectively

TABLE VI Positive GCF tests in relation to duration of symptoms, by sex

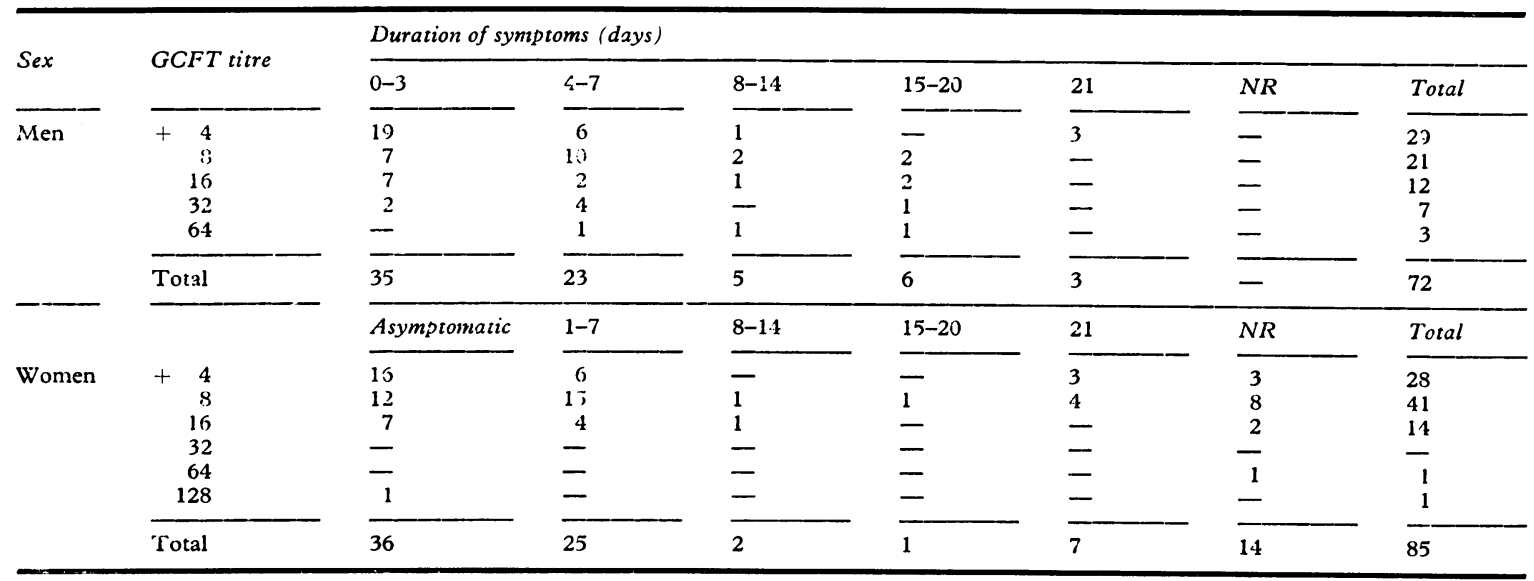

these 61 patients who were either asymptomatic or had symptoms of 7 days' duration or less gave a definite past history of gonorrhoea. The duration of symptoms was over 7 days in ten, and had not been recorded in fourteen. Since gonorrhoea is so frequently asymptomatic in women, it is rarely possible to assess the duration of the disease. The high incidence of past gonorrhoea in patients with symptoms of less than 7 days' duration suggests that some of these positive reactions could well have been due to previous infections.

The duration of symptoms had been recorded in 398 of the 400 cases of uncomplicated gonorrhoea in men. A positive GCFT was found in $35(12.9$ per cent.) of the 271 cases presenting within 3 days of the onset of symptoms (Table VII). Of the 100 patients presenting 4 to 7 days after the onset of symptoms, 23 (23 per cent.) were seropositive. Of the eleven patients with symptoms of 8 to 14 days' duration, five (nearly half) had positive serological test results

TABLE VII Proportion of positive GCF tests in relation to duration of symptoms

\begin{tabular}{|c|c|c|c|c|c|}
\hline \multirow{2}{*}{$G C F T$} & \multicolumn{5}{|c|}{ Duration of symptoms (days) } \\
\hline & $0-3$ & 4-7 & $8-14$ & $>14$ & Total \\
\hline Negative & 236 & 77 & 6 & 7 & 326 \\
\hline $\begin{array}{l}\text { Positive No. } \\
\text { Per cent. }\end{array}$ & $\begin{array}{l}35 \\
12 \cdot 9\end{array}$ & $\begin{array}{l}23 \\
23\end{array}$ & $\begin{array}{c}5 \\
45 \cdot 6\end{array}$ & $\begin{array}{c}9 \\
56 \cdot 3\end{array}$ & $\begin{array}{l}72 \\
18\end{array}$ \\
\hline
\end{tabular}


compared with nine (over half) of the sixteen presenting with symptoms of over 14 days' duration. The differences between these proportions are statistically significant and indicate a direct relationship between the frequency of a positive GCFT and the duration of symptoms.

In the cases of men suffering from uncomplicated gonorrhoea, the GCFT titre was $1: 64$ in three, $1: 32$ in seven, $1: 16$ in twelve, $1: 8$ in twenty-one, and $1: 4$ in twenty-nine (Table VI). In the cases of women suffering from uncomplicated gonorrhoea there was a titre of $1: 128$ in one and $1: 64$ in another. The titre was $1: 16$ in fourteen, $1: 8$ in 41 , and $1: 4$ in 28 . There appeared to be no correlation between a rising titre and the duration of the disease, but the figures are not large enough for reliable assessment.

High titres (1:16 or above) were found in five of 25 seropositive male 'controls' and in ten of 34 seropositive female 'controls'. A past history of gonorrhoea or of genital inflammation had been recorded in the cases of two of the five males and in five of the ten females with high titres (Table VIII).
The Africans had the highest seropositivity rate (29.4 per cent.) among men (fifteen positives in 51 patients) (Table IX). The West Indians came next with 15.7 per cent. ( 25 positives in 159 patients), and the Asians next with $\mathbf{9 . 4}$ per cent. (ten positives in 107 patients). Among the seropositive men the Africans gave a past history of urethritis in a higher proportion of cases (ten of fifteen: 66 per cent.) than any of the other nationalities. West Indians gave such a history in 62.5 per cent. of cases and Europeans in 37.2 per cent. Four of the ten seropositive Asians admitted to having had urethritis previously.

Seropositive African and Asian women were too few in number to allow valid conclusions to be drawn. The highest proportion of positive reactions occurred among the West Indian women, namely 27 in 124 cases (21.8 per cent.). The comparable figure for Europeans, namely 105 in 608 cases (17.3 per cent.) was somewhat lower. A past history of genital inflammation had been recorded in the cases of seven of the 27 West Indians ( 26 per cent.) and 42 of the 105 Europeans ( $41 \cdot 2$ per cent.).

TABLE VIII Titre of positive GCF tests in the various groups of patients, by sex

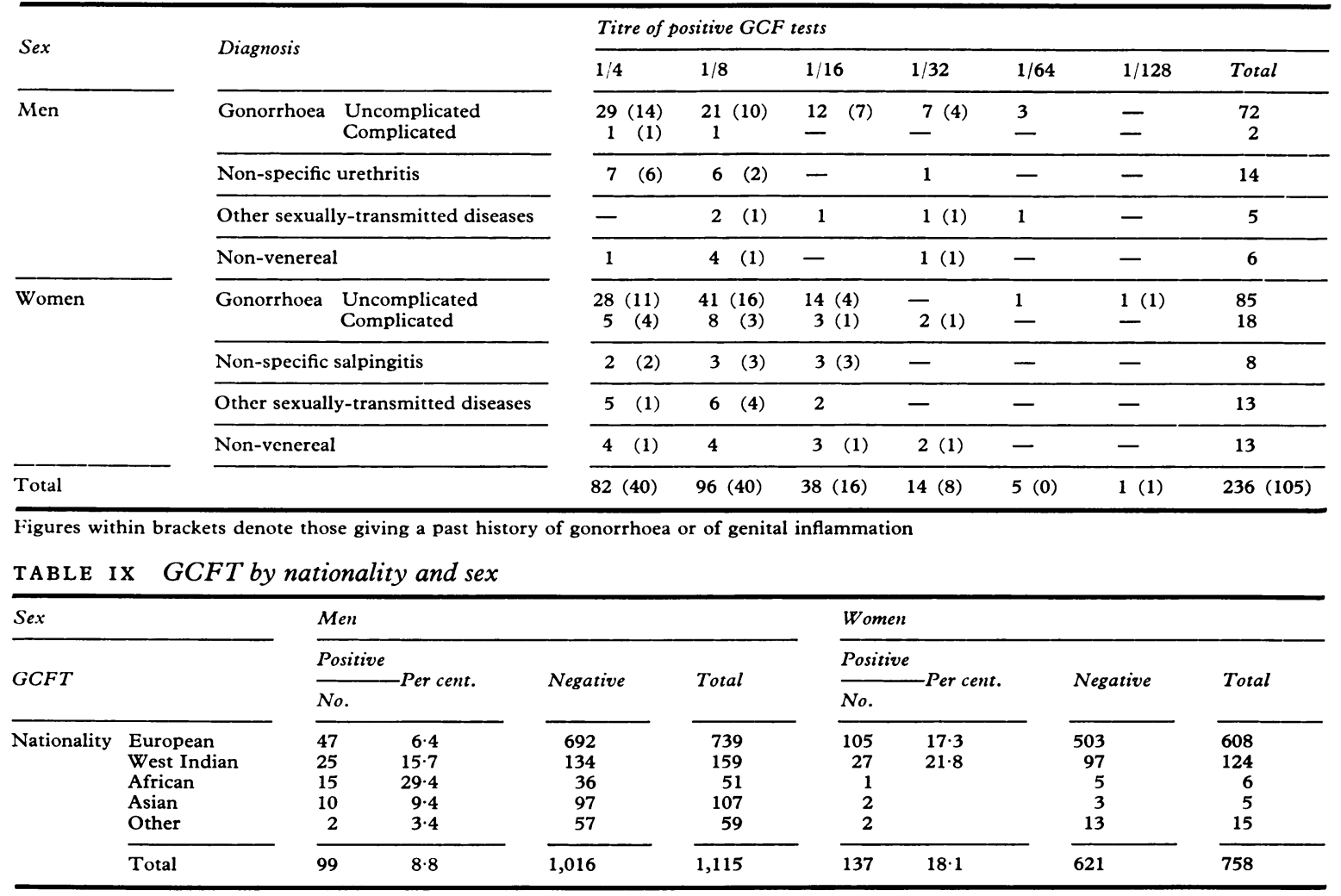

Titre of positive GCF test 
The Figure shows the confidence limits for $P$ in graphical form of the incidence of seropositivity in the different nationalities. In the cases of men, seropositivity is significantly more common in Africans than in Asians and Europeans, while the incidence for West Indians lies in between. Although seropositivity is significantly more common in West Indian men than in European men, there is no significant difference in seropositivity in women between these two nationalities. The Figure also shows that seropositivity is significantly more common in women than men.

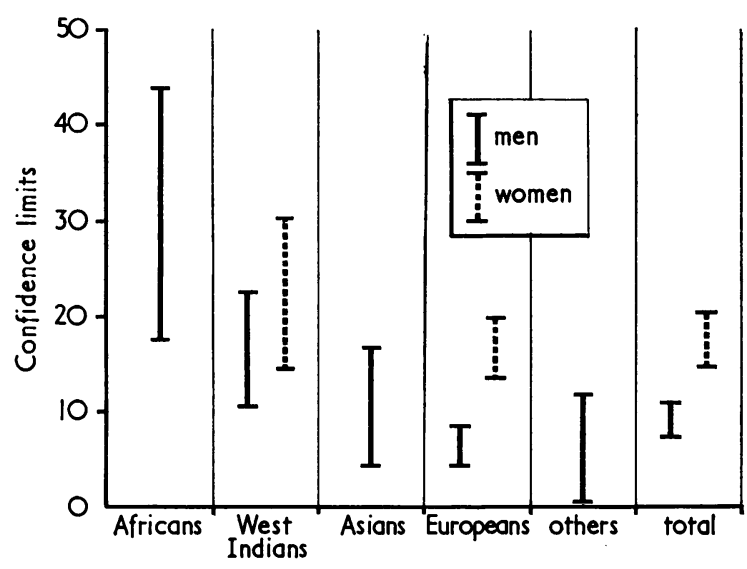

FI GURE Seropositivity in patients of different nationalities, by sex. Confidence limits for $P$

Although it was intended to repeat the GCFT 3 months after treatment, this was done only for 24 of the 74 male patients and 29 of the 103 female patients suffering from gonorrhoea and having positive GCFT results. Among the men seronegativity was reached between 2 and 7 months after treatment in ten cases, while the test remained positive for between 1 and 5 months or more in fourteen cases. Among the women eleven became seronegative between 3 weeks and 8 months after treatment, while eighteen remained seropositive for 1 to 8 months or more after treatment.

\section{Discussion}

INCIDENCE OF SEROPOSITIVITY IN THE VARIOUS GROUPS OF PATIENTS

In the present study the GCFT was found to be more frequently positive in gonorrhoea than in any of the comparison groups. As in the findings of Schmidt (1961) and Magnusson and Kjellander (1965), the test was positive about twice as frequently in uncomplicated gonorrhoea in women as it was in men. This same ratio was observed in the comparable comparison groups as well as in the whole series, but the difference in the comparison groups, as stated earlier, was not statistically significant. The absence of a significant difference between the seropositivity rates in complicated and uncomplicated gonorrhoea in women may be due to the presence of subclinical complications in the latter.

It is understandable that the test should be more frequently positive in the female than in the male because women have usually had the disease longer than men before examination. Osmond and Oliver (1929) showed that the frequency of positive reactions increased with the duration of the disease from 12.4 per cent. in the first 10 days to 52.3 per cent. in 10 to 21 days and 61.4 per cent. in 21 days to one year (among males and females grouped together). Price (1931) also recorded an increasing frequency of positive reactions with increasing duration of infections. A similar trend was noted in the present series (Table VII).

Magnusson and Kjellander (1965) thought that the higher seropositivity rate in women could be due to the larger area of mucous membrane involved compared with the area in men. Against this view is the finding of only one positive reaction among the eleven male cases of gonococcal proctitis in the present series (Table II). Harkness (1944) found only eight cases in which the test results were positive among 110 cases of ano-rectal gonorrhoea in men; there was a past history of gonococcal urethritis in two of the eight positive cases, as there was in the one case in the present study. In gonorrhoea in women there was no significant difference in the proportion of positive reactions among those with proctitis and those without. It is, therefore, more likely that the greater frequency of seropositivity in women than in men is due to the longer duration of the disease in women before examination.

Magnusson and Kjellander (1965) found no positive reactors among fifty healthy blood donors and 52 patients with dermatoses. Osmond (1922) found a rather lower frequency of positive reactions in his non-gonorrhoeal group than that reported here, namely two positives among 61 men and one among 53 women. The difference between Magnusson and Kjellander's findings and those of Osmond and of the present study may be due to the fact that the patients in the two latter series, though not suffering from gonorrhoea, came from clinics for sexuallytransmitted disease.

In cases of non-specific salpingitis the GCFT was positive in 12.5 per cent., an incidence much higher than that found in any of the other comparison groups. The view generally held is that gonococci are rarely found in and around the Fallopian tubes in 
gonococcal salpingitis (Falk, 1965). However, Lip and Burgoyne (1966), in an investigation of 49 patients with acute salpingitis and twelve uninfected patients, reported positive peritoneal cultures for gonococci in three cases in which cultures from the cervix were negative. Dietrich, Lodenkämper, and Nickel (1965) found gonococci in the adnexal exudates of all of eleven patients with chronic salpingo-oophoritis. Some of the cases diagnosed as non-specific salpingitis in the present study could have been gonococcal and this may partly account for the greater frequency of seropositivity in this category. Moreover, treatment would usually have been started after only one examination on account of the signs of salpingitis. Some cases might have proved to be gonococcal had the circumstances permitted a second or third examination before treatment. A more likely reason - that of past gonococcal infection - is discussed later.

\section{PAST HISTORY OF URETHRITIS OR GENITAL INFECTION}

A past history of urethritis or of genital inflammation was significantly more frequent in those cases in which the GCFT was positive among both men and women than in those in which the test results were negative. This strongly suggests that some of the positive results were due to previous attacks of gonorrhoea. There is further support for this view in that, in as many as 50 per cent. of seropositive males having gonorrhoea, the duration of symptoms was less than 3 days. Again, the frequency of a past history of urethritis in seropositive men was directly related to the frequency of positive reactions in the various racial groups.

A past history of genital inflammation was much more frequently present in seropositive cases of nonspecific salpingitis (100 per cent.) as well as in seronegative cases ( 50 per cent.) than even in gonorrhoea. It is reasonable to infer that some of these positive reactions were due to past gonococcal infections, thus accounting for the higher seropositivity rate in nonspecific salpingitis than in any other comparison group.

\section{PAST HISTORY OF BRONCHITIS AND/OR ASTHMA}

There was no significant difference with regard to a past history of bronchitis or asthma or of both between those patients with a positive GCFT and those with a negative test result. Bang and Krag (1942), in a study of gonorrhoeal infection among 1,895 cases treated in a medical service, found the GCFT positive in 7.2 per cent. of men and 6.2 per cent. of women. Of the men with a positive GCFT, 22.2 per cent. had chronic bronchitis, while the corresponding figure in the control group was 6.9.
A similar situation though somewhat less pronounced, was found in women. The chronic bronchitis cases in which the GCFT was positive were generally severe. Lange, Reyn, Bentzon, and Lind (1966), in an investigation of the GCFT in 1,601 patients $(1,106$ pulmonary patients and 495 from the surgical wards as controls) in Greenland, found positive results in 49 per cent. of tuberculous patients with bronchitis and/or bronchiectasis, in 24 per cent. of such patients without this complication, and in 17 per cent. of surgical controls. These high figures suggest that they were obtaining many false positive results. They further noted that the incidence of positivity of the GCFT increased with the increasing extent of the pulmonary process, bronchial involvement being a significant factor. The activity of the pulmonary tuberculosis was not correlated with the incidence of a positive GCFT.

Findings in this survey indicate that confusion resulting from false positives due to chronic bronchitis can be discounted, because to be of any significance the bronchitis should be well advanced; but it must be acknowledged that this opinion may not be valid for cases examined in cities with high bronchitis rates.

\section{DURATION OF SYMPTOMS IN RELATION TO A POSITIVE GCFT}

Although Price (1938) considered that positive reactions could be obtained in cases of untreated gonorrhoea at any time from the first week after exposure to infection and Osmond (1938) thought they occurred a little later, the general view is that the test takes some weeks to become positive in uncomplicated gonorrhoea (Topley and Wilson, 1964; King and Nicol, 1969). The fact that as many as 12.9 per cent. of men suffering from uncomplicated gonorrhoea were seropositive within 3 days of the onset of symptoms suggests that some of these positive results were due to previous gonococcal infections. As already mentioned, there was a direct relationship between the incidence of positivity and the duration of symptoms.

Positive tests in high titre (1:16 or above) occurred in the comparison groups as well as in gonorrhoea, and did not therefore help in establishing a diagnosis of gonorrhoea.

\section{PERSISTENCE OF A POSITIVE GCFT}

Previous workers have been of the opinion that a positive GCFT in uncomplicated gonorrhoea became negative within a few months of cure, while in complicated gonorrhoea a positive reaction might persist for years. Thus, Price (1931) followed fifty cases of uncomplicated gonorrhoea and concluded that a positive reaction became negative in 3 to 4 
months after cure. Osmond (1938) thought that certain cases, e.g. prostatitis and epididymitis, yielded positive results more or less indefinitely and drew a parallel to 'Wassermann fastness' in late syphilis. Harkness (1940) supported the view that once gonococcal antibodies had been produced they might persist for many years. He carried out tests in sixty cases of stricture of the urethra, in which the most recent gonococcal infection had occurred 35 years previously; strongly positive reactions were found in 33 per cent. but in no case was the gonococcus found in the urinary tract. According to Osmond (1938), Dorffel followed up 126 cases of gonorrhoea, of which nine were positive after one year, seven after 2 to 5 years, and one each after $7,8,14,17$, and 35 years. If we consider the parallel Wassermann reaction, could we also accept a state of latency in gonorrhoea? King (1949) suggested that penicillin acted in some cases as a short cut to latency in gonorrhoea. It is difficult to be dogmatic. All that can be said is that a positive reaction indicates past or present gonorrhoea in most instances. It is not now possible to determine in every case whether an active focus of infection is present or not.

The material in this study is not suitable for assessment regarding the persistence of a positive test because insufficient cases have been followed-up. In the few cases in which the test was repeated it remained positive after treatment for 1 to 8 months or more in the majority. The significantly more frequent finding of a past history of urethritis or of genital inflammation in those with a positive GCFT as compared with those with a negative test also suggests that a positive reaction does persist for a considerable period of time.

\section{Conclusion}

The sensitivity of the GCFT leaves much to be desired in uncomplicated gonorrhoea as it was positive in only 18 per cent. of men and 34 per cent. of women. Even in complicated gonorrhoea in the female, positive reactions were obtained in only 41 per cent. of cases. As a diagnostic test it cannot be classed in the same category as the serological tests for syphilis. Admittedly, Ramanarayana Murti and others (1962) and Magnusson and Kjellander (1965) obtained much higher proportions of positive results, particularly in complicated gonorrhoea, but since neither paper mentions previous infections in the cases studied, one wonders how many positive results were due to the infections under investigation and not to previous ones.

The specificity of the test is not particularly good. Magnusson and Kjellander (1965) found 1.3 per cent. positive results in cases in control groups. Osmond (1922) recorded seropositivity in 2 per cent. of men and 3 per cent. of women among patients not suffering from gonorrhoea. In the present study the rate of positivity was between 2.5 and 6.5 per cent. in the comparison groups, excluding non-specific salpingitis. The reason for the higher figure of 12.5 per cent. in non-specific salpingitis has already been discussed. Furthermore, Lange and others (1966) found 17 per cent. positive results in surgical control cases. As far as can be seen the only condition, other than gonorrhoea, that can give a high seropositivity rate is severe chronic bronchitis.

As the GCFT is more frequently positive in cases of gonorrhoea than in any of the comparison groups, there must be a causal relationship between a positive result and gonorrhoea. However, the low rate of seropositivity and the rarity of serious systemic complications in gonorrhoea do not warrant the routine performance of the test on all patients attending a venereal disease clinic. There seems to be a case for carrying out the test when gonorrhoea is suspected but genital or other local tests do not reveal the presence of the gonococcus. The finding of a positive GCFT might suggest a gonococcal infection, provided chronic bronchitis were excluded. If the test is to be used in problem cases, it should be performed only in laboratories in which sera are tested regularly, because, as stressed in the literature, the closest technical attention, especially in the preparation of the antigen and in the adjustment of the haemolytic system, is required. Reliable results are unlikely to be obtained in a laboratory in which the test is performed only occasionally.

When a positive reaction is found in such circumstances, the demonstration of gonococci in the sexual contacts of the patient would suggest the presence of gonococci in the original patient. But if the findings in the contacts are negative the positive GCFT result is probably the consequence of a previous infection.

Newer tests, such as the Rapid Biochemical Test (Pedersen and Kelly, 1966) or the Passive Haemolysin Test (Maeland, 1966), may prove better than the GCFT. A microprecipitin test (Chacko and Nair, 1969) shows promise, but still cannot differentiate between past and present gonorrhoea. Until the superiority of these tests is established it would be unwise to discard the GCFT altogether. Using selected antigen preparations in the GCFT, Reising, Schmale, Danielsson, and Thayer (1969) reported 88.2 per cent. seropositivity in women with gonorrhoea, but only 27.6 per cent. in men. Further improvement of these antigen preparations may provide a more reliable test for routine use. 


\section{Summary}

The results of the GCFT in 1,873 patients have been evaluated.

A positive reaction was found in uncomplicated gonorrhoea twice as frequently in the female ( 34 per cent.) as in the male (18 per cent.). In complicated gonorrhoea in the female the test was positive in a higher proportion of cases (41 per cent.) but this difference from the uncomplicated cases was not statistically significant.

The seropositivity rates in the groups compared varied between 2.5 and 6.5 per cent., except in nonspecific salpingitis in which it was 12.5 per cent. Reasons for this high figure are suggested.

A past history of urethritis or of genital inflammation was present in a significantly higher proportion of those with positive reactions than in those with negative results, suggesting the persistence of seropositivity from previous infections.

There was no significant difference in the frequency of a past history of bronchitis or asthma or both between seropositive and seronegative patients.

Since the sensitivity of the test is low it is felt that there is no reason to perform the test routinely on all patients attending V.D. clinics. It may be helpful in problem cases, but in such cases the sera should be examined in a laboratory where the GCFT is performed regularly.

I wish to thank Dr. E. M. C. Dunlop for suggesting this investigation and for his valuable help in the preparation of this paper. My thanks are also due to Dr. P. Rodin and Dr. A. E. Wilkinson for their help. I am grateful to Dr. D. W. Vere for his advice on the statistical assessment of the results obtained. I should also like to thank Miss J. Robertson for typing the manuscript and Miss J. Evendon and her colleagues for collecting the case notes.

\section{References}

BANG, O., and KRAG, P. (1942) Ugeskr. Laeg., 104, 406

CHACKo, C. W., and NaIR, G. M. (1969) Brit. J. vener. Dis., 45, 33

DieTrich, H., LODENKÄMPER, H., and NiCKel, H. (1965) Geburtsh. Frauenheilk., 25, 822

Falk, V. (1965) Acta obstet. gynaec. scand., 44, Suppl. 6, p. 7

HARKNESS, A. H. (1940) Brit. F. vener. Dis., 16, 211

- (1944) Ibid., 20, 81

KING, A. J. (1949) Ibid., 25, 77

- and Nicol, C. S. (1969) 'Venereal Diseases', 2nd ed., p. 156. Baillière, Tindall and Cassell, London

Kolmer, J. A., and Brown, C. P. (1914) f. infect. Dis., 15, 6

Lange, P. K., Reyn, A., Bentzon, M. W., and Lind, I. (1966) Ugeskr. Laeg., 128, 409
LIP, J., and Burcoyne, X. (1966) Obstet. and Gynec. $\stackrel{\vec{F}}{\stackrel{\overrightarrow{9}}{+}}$ (N.Y.), 28, 561

MaELAND, J. A. (1966) Acta path. microbiol. scand., 67, 102

Magnusson, B., and KJellander, J. (1965) Brit. F. vericr. Dis., 41, 127

MülleR, R., and Oppenhrim, M. (1906) Wien. Klin. Wschr., 19, 894

OsmoNd, T. E. (1922) Lancet, 1, 1143

- (1938) Brit. F. vener. Dis., 14, 169

- and OlIVER, J. O. (1929) Ibid., 5, 281

Pedersen, A. H. B., and Kelly, R. E. (1965) Pukl. Filth Rep. (Wash.), 81, 318

Price, I. N. OrPWOOD (1931) Brit. med. F., 1, 578

- (1933) London County Council Publications, No. 2995, p. 9

- (1938) Brit. F. vener. Dis., 14, 153

- (1949a) Ibid., 25, 67

- (1949b) Ibid., 25, 157

- (1950) Ibid., 26, 33 and 172

Ramanarayana Murti, B., Rajyalakshmi, and Perin Devi, B. (1962) Indian F. Microbiol. (Calcutta), JulySept., 2, No. 3, 107

Reising, G., Schmale, J. D., Danielsson, D. G., and Thayer, J. D. (1969) Appl. Microbiol., 18, 337

Schmidt, H. (1961) Ugeskr. Laeg., 123, 749

Schwartz, H. J., and MCNeIL, A. (1911) Amer. f. med. Sci., 141, 693

- (1912) Ibid., 144, 815

Shupe, T. P. (1916) Cleveland med. F., 15, 652

TEAgue, O., and ToRrey, J. C. (1907) f. med. Res., 17, 223

Topley, W. W. C., and Wilson, G. S. (1964) 'Topley and Wilson's Principles of Bacteriology and Immunity', 5th ed., by G. S. Wilson and A. A. Miles, p. 1759. Arnold, London.

Weiss, E., and ArNold, L. (1938) Amer. F. Syph., 22, 310

Wilkinson, A. E. (1952) Brit. F. vener. Dis., 28, 24

Valeur de l'épreuve de fixation du complément dans la gonococcie

SOMMAIRE

Les résultats de cette réaction de fixation du complément $\mathbb{N}$ ont été évalués chez 1.873 malades.

Dans la gonococcie non compliquée, une réaction $\mathcal{O}^{-}$ positive a été trouvée deux fois plus fréquemment chez la $\mathrm{N}$ femme (34 pour cent) que chez l'homme (18 pour cent). Dans la gonococcie compliquée de la femme, l'épreuve a été positive dans une plus grande proportion de cas (41 pour cent) mais cette différence par rapport aux cas $\stackrel{\mathbb{Q}}{\rightarrow}$ non compliqués n'est pas statistiquement significative.

Les taux de séro-positivité dans les groupes ayant fait $\underline{T}$ l'objet de ces comparaisons varient entre 2,5 et 6,5 pur cent, sauf dans la salpingite non spécifique dans laquelle il fut trouvé à 12,5 pour cent; on suggère des explications $\stackrel{\mathbb{D}}{\mathbb{Q}}$ pour ce chiffre important.

En cas de résultats positifs, des antécéaente d'urétrite ou d'inflammation génitale existaient aans une pro- 
portion significativement plus élevée par rapport aux résultats négatifs; ceci suggère que la séro-positivité peut persister après des infections antérieures.

Il n'y eut pas de différence significative parmi les malades séro-positifs et séro-négatifs lorsqu'il existait des antécédents de bronchite ou d'asthme, ou des deux infections.
Etant donné la faible sensibilité de l'épreuve, on pense qu'il n'y a pas de raison de la pratiquer en routine chez tous les malades se présentant dans les cliniques de vénéréologie. Elle peut être utile dans les cas difficiles mais, dans de tels cas, les sérums doivent être examinés dans un laboratoire où la réaction est pratiquée régulièrement. 